Adejumo et al., Afr., J. Infect. Dis. (2017) 11 (2): 75-82

https://doi.org/10.21010/ajid.v11i2.10

\title{
FACTORS ASSOCIATED WITH TB/HIV CO-INFECTION AMONG DRUG SENSITIVE TUBERCULOSIS PATIENTS MANAGED IN A SECONDARY HEALTH FACILITY IN LAGOS, NIGERIA
}

\section{Olusola A. Adejumo ${ }^{a}$, Olusoji J. Daniel ${ }^{b}$, Andrew F. Otesanyac ${ }^{c}$, Adebukola A. Adegbolad, Temitope Femi- Adebayo $^{a}$. Abimbola Bowale ${ }^{\mathrm{e}}$, Sunday Adesola ${ }^{\mathrm{e}}$, Olugbenga O. Kuku ${ }^{\mathrm{e}}$, Kehinde O. Otemuyiwa ${ }^{\mathrm{e}}$, Shafaatu N. Oladega ${ }^{\mathrm{e}}$, Eze O. Johnson ${ }^{\mathrm{e}}$, Ayodeji A. Falana ${ }^{\mathrm{e}}$, Olusola Dawodu ${ }^{\mathrm{e}}$, Henry Owuna ${ }^{\mathrm{e}}$, Ganiyat Osoba ${ }^{\mathrm{e}}$, Adetokunbo Dacosta ${ }^{\mathrm{e}}$}

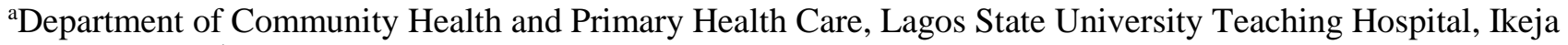

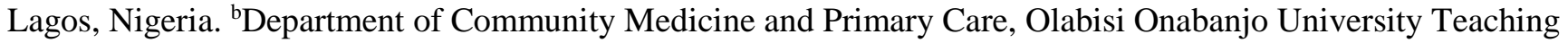
Hospital Sagamu Ogun State. ${ }^{\mathrm{c}}$ Medical Services Department, Central Bank of Nigeria, Lagos. ${ }^{\mathrm{d}} \mathrm{KNCV}$ TB

Foundation Nigeria/ Challenge TB project, Abuja, Nigeria. ${ }^{\mathrm{e}}$ Mainland Hospital, Yaba, Lagos, Nigeria.
\end{abstract}

Corresponding Author's E-mail: drolus_adejumo@yahoo.com, oluadejumo75@gmail.com

\begin{abstract}
Background: This study assessed factors associated with TB/HIV co-infection among TB patients managed in a secondary health facility in Lagos Nigeria.

Materials and Methods: A retrospective review of treatment cards of patients seen at a secondary referral hospital between January 12014 and December 312014 was conducted. Treatment outcomes and factors associated with TB/HIV co-infection were assessed.

Results: Of the 334 records of patients reviewed, the proportion of patients with TB/HIV co-infection was 21.6\%. The odds of having TB/HIV co-infection was 2.7 times higher among patients above 40 years than patients less than 25 years (AOR $2.795 \%$ CI $1.1-6.5, \mathrm{p}=0.030$ ). In addition, the odds of having TB/HIV co-infection was 3.3 higher among extrapulmonary TB cases (AOR 3.3; 95\% CI $1.2-9.5 ; \mathrm{p}=0.026$ ) and 2.1 times higher among retreated patients (AOR 2.1; 95\% CI $1.1-3.9 ; \mathrm{p}=0.017)$ than pulmonary TB and new patients respectively. The chance of having TB/HIV co-infection was 2.7-fold more in patients with poor treatment outcomes than patients with treatment success (AOR 2.7; 95\%CI 1.3 - 5.4; p $=0.006)$.

Conclusion: TB/HIV co-infection rate was high in the study area. There is need to put measures in place to improve treatment outcomes of TB/HIV co-infected patients.
\end{abstract}

Key Words: TB, HIV, co-infection, Nigeria

\section{Introduction}

Tuberculosis (TB) and human immune deficiency virus (HIV) co-infection is a serious public health challenge because of associated mortality globally (WHO, 2015). Of the nine million incident TB cases reported in 2013, 13\% had HIV and the African Region had the highest TB/HIV co-infection rate at 34\% (WHO, 2014). Globally, people living with HIV (PLWHA) are about 30 times more likely to develop TB than HIV-negative individuals (WHO, 2014). In 2013, an excess of 25\% deaths among TB patients were due to HIV co-infection, the majority of which were from the African Region (WHO, 2014). HIV was partly responsible for the failure to meet TB control targets especially in countries with high prevalence of HIV (FMOH Ethiopia, 2009).

TB and HIV constitute lethal combination of diseases that significantly impacts the public health system individually and collectively. HIV infection weakens the immune system which in turn increases the risk of TB infection. It is the most powerful risk factor for reactivation of latent TB infection to active disease (FMOH Nigeria, 2013). On the other hand, the course of HIV infection is usually accelerated by TB infection which may be the first opportunistic infection and a leading cause of death in individuals infected with HIV (WHO, 2012).

TB burden in Nigeria (318 per 100,000) is one of the highest in the world (WHO, 2014) and according to the National Agency for the Control of AIDS (NACA) the prevalence of HIV in Nigeria is 3.4\% as at 2012 (NACA, 2012). However, the proportion of patients with TB/HIV co-infection in Nigeria is 19.1\% (NTBLCP, 2014). Several studies from Nigeria and other high TB burden countries have shown that TB/HIV co-infected patients have poorer treatment outcomes (Daniel and Alausa, 2006; Ofoegbu and Odume, 2015; Tweya et al. 2013; Payam et al, 2012). This study assessed factors associated with TB/HIV co-infection among TB patients managed at a secondary health facility in Lagos Nigeria. 
Adejumo et al., Afr., J. Infect. Dis. (2017) 11 (2): 75-82

https://doi.org/10.21010/ajid.v11i2.10

\section{Materials and Methods \\ Study design}

A retrospective review of treatment cards of patients seen at a secondary referral hospital between January 12014 and December 312014 was conducted.

\section{Study background}

This study was carried out at the directly observed treatment short course (DOTS) clinic of Mainland hospital in Lagos Nigeria. Lagos state is located in the South-western part of Nigeria and has a population of about 21 million people. There are 20 Local Government Areas (LGAs) and 37 Local Council Development Areas in the state. Mainland hospital is a secondary health facility established in 1930 as a sanatorium to serve as an infectious disease hospital. The name was changed to Mainland Hospital in 2003. Presently, the hospital serve as a referral center for the management of infectious diseases like TB, multi drug resistant TB, HIV/AIDS, Cholera, Ebola virus disease and Lassa fever.

\section{Coordination of TB control in Lagos State}

The DOTS management of TB commenced in Lagos State in 2003 and is coordinated by the Lagos State TB and Leprosy Control Programme (LSTBLCP). By 2014 there were 317 (214 public and 103 private) DOTS facilities in the state. TB drugs supplied by the National TB and Leprosy Control Programme (NTBLCP) were given to patients at no cost. In addition, patients were not charged for sputum microscopy, Gene Xpert and HIV tests. TB treatment duration was six months divided into 2 months' intensive and 4 months' continuation phase. Rifampicin, Isoniazid, Pyrazinamide and Ethambutol as fixed dose combination were given during the intensive phase while during the continuation phase, Rifampicin and Isonizid as fixed dose combination were given. HIV test was conducted for all presumptive TB clients. Determine (determine HIV-1/2 Alere Determine ${ }^{\mathrm{TM}}$, Japan 2012) and Uni-Gold ${ }^{\mathrm{TM}}$ (Trinity Biotech PLC, Wicklow, Ireland 2013) were used in parallel algorithm. However, STAT-PAK® was used as tie breaker when there was discordant result.

\section{Definition of outcome variable}

a) Cured: This was the proportion of smear positive patients that complete treatment and had at least two negative smears with an interval of at least one month, one of which should be obtained at the end of treatment.

b). Treatment completed: This was the proportion of patients that completed treatment but sputum examination results are not available or smear negative patients that completed treatment.

c) Died: The proportion of patients that died from any cause before completion of treatment.

d). Default: This was the proportion of patients that did not take drugs for at least two consecutive months.

e). Treatment failure: This was the proportion of patients who were sputum smear positive at five months or more after the commencement of treatment, or patients who interrupted treatment for more than 2 months after completing one month of chemotherapy afterwards returned to treatment and were found to be smear positive

f). Treatment success: This is the sum of the cases that were cured and that completed treatment.

\section{Data analysis}

Data was analyzed using Statistical Package for Social Sciences (SPSS) IBM version 19. Percentages, mean and standard deviation of numerical variables were determined. Chi squared test and Fisher's exact test were used to compare categorical variables as the case may be. Crude and adjusted odds ratio of associated factors were determined. Confidence interval was set at $95 \%$ for all statistical test. Records with complete data were included for analysis.

\section{Ethical issues}

Data for this study were retrieved from secondary data routinely collected at Mainland Hospital. Permission for data collection was obtained from the LTBLCP and the management of Mainland Hospital. 
Adejumo et al., Afr., J. Infect. Dis. (2017) 11 (2): 75-82

https://doi.org/10.21010/ajid.v11i2.10

\section{Results}

Of the 334 records of patients reviewed, the majority $224(67.1 \%)$ were between 20 - 39 years. Mean age was $32.2 \pm 11.0$ years. The majority were males $(75.4 \%)$ while $236(70.7 \%)$ were new cases. The proportion of TB/HIV coinfected patients was $21.6 \%$ and of the $312(93.4 \%)$ with pulmonary TB, $216(69.2 \%)$ were smear positive as shown in Table 1.

Table 1: Demographic and tuberculosis profile of patients

\begin{tabular}{lll}
\hline Variable & Frequency $(\mathbf{n}=\mathbf{3 3 4})$ & $\mathbf{\%}$ \\
\hline Age group (years) & 30 & \\
$<20$ & 224 & 6.0 \\
$20-39$ & 68 & 20.4 \\
$40-59$ & 12 & 3.6 \\
$\geq 60$ & $32.3 \pm 11.0$ & \\
Mean \pm SD & & \\
Gender & 252 & 75.4 \\
Male & 82 & 24.5 \\
Female & & \\
Type of TB & 312 & 93.4 \\
Pulmonary & 22 & 6.6 \\
Extra-pulmonary & & \\
Treatment category & 236 & 70.7 \\
New & 98 & 29.3 \\
Retreatment & & \\
Had treatment supporter & 208 & 62.3 \\
Yes & 126 & 37.7 \\
No & & 78.4 \\
HIV status & 262 & 21.6 \\
Negative & 72 & \\
Positive & $\mathbf{n}=\mathbf{3 1 2}$ & \\
Smear result & 216 & \\
Positive & 96 & \\
Negative & & \\
& & \\
\hline
\end{tabular}

The odds of having TB/HIV co-infection was 2.7 times higher among patients above 40 years patients less than 25 years (AOR $2.795 \%$ CI $1.1-6.5, \mathrm{p}=0.030$ ). In addition, the odds of having TB/HIV co-infection was 3.3 higer among extra-pulmonary TB cases (AOP 3.3; 95\% CI $1.2-9.5 ; \mathrm{p}=0.026)$ and 2.1 times higher among patients $(\mathrm{AOR} 2.1 ; 95 \%$ CI $1.1-3.9 ; \mathrm{p}=0.017)$ than pulmonary TB and new patients respectively. The chance of having TB/HIV co-infection was 2.7-fold more in those with poor treatment outcomes than those with treatment success (AOR 2.7; 95\%CI 1.3 - 5.4; p $=0.006)$ (Table 2). 
Adejumo et al., Afr., J. Infect. Dis. (2017) 11 (2): 75-82

https://doi.org/10.21010/ajid.v11i2.10

Table 2: Regression analysis of associated factors of TB/HIV co-infection

\begin{tabular}{|c|c|c|c|c|}
\hline Variable & $\begin{array}{l}\text { TB/HIV } \\
n=72(\%)\end{array}$ & $\begin{array}{l}\text { TB } \\
n=262(\%)\end{array}$ & COR $(95 \%$ CI $), p$ & $\operatorname{AOR}(95 \% \mathrm{CI}), \mathrm{p}$ \\
\hline \multicolumn{5}{|l|}{ Age group } \\
\hline$<25$ & $10(12.2)$ & $72(87.8)$ & 1 & \\
\hline $25-39$ & $40(23.3)$ & $132(76.7)$ & $2.2(1.0-5.0), 0.038$ & $2.1(0.9-4.6), 0.072$ \\
\hline$\geq 40$ & $22(27.5)$ & $58(72.5)$ & $2.7(1.1-6.8), 0.014$ & $2.7(1.1-6.5), 0.030$ \\
\hline \multicolumn{5}{|l|}{ Gender } \\
\hline Female & $20(24.4)$ & $62(75.6)$ & $1.2(0.7-2.3), 0.473$ & $1.6(0.9-3.1), 0.135$ \\
\hline Male & $52(20.6)$ & $200(79.4)$ & 1 & \\
\hline \multicolumn{5}{|l|}{ Type of TB } \\
\hline Extra-pulmonary & $10(45.5)$ & $12(54.5)$ & $3.4(1.3-8.8), 0.0124$ & $3.3(1.2-9.5), 0.026$ \\
\hline Pulmonary & $62(19.9)$ & $250(80.1)$ & 1 & \\
\hline \multicolumn{5}{|l|}{ Type of patient } \\
\hline Retreated & $26(26.5)$ & $72(73.5)$ & $1.5(0.8-2.7), 0.154$ & $2.1(1.1-3.9), 0.017$ \\
\hline New & $46(19.5)$ & $190(80.5)$ & 1 & \\
\hline \multicolumn{5}{|l|}{ Treatment outcome } \\
\hline No treatment success & $18(39.1)$ & $28(60.9)$ & $2.8(1.4-5.7), 0.002$ & $2.7(1.3-5.4), 0.006$ \\
\hline Treatment success & $54(18.8)$ & $234(81.2)$ & 1 & \\
\hline
\end{tabular}

$\mathrm{NB}: \mathrm{COR}=$ Crude odds ratio, $\mathrm{AOR}=$ Adjusted odds ratio 
Adejumo et al., Afr., J. Infect. Dis. (2017) 11 (2): 75-82

https://doi.org/10.21010/ajid.v11i2.10

Table 3 shows that a significantly higher proportion of TB patients were cured than TB/HIV co-infected patients (37.4\% vs $22.2 \%$; $\mathrm{p}=0.016)$ however, more TB/HIV co-infected patients died than TB patients $(11.1 \%$ vs $2.3 \%$; 0.003$)$

Table 3: Treatment outcome in TB/HIV co- infected and TB patients

\begin{tabular}{llll}
\hline Variable & $\begin{array}{l}\text { TB/HIV } \\
\mathbf{n}=\mathbf{7 2}(\boldsymbol{\%})\end{array}$ & $\begin{array}{l}\mathbf{T B} \\
\mathbf{n}=\mathbf{2 6 2}(\boldsymbol{\%})\end{array}$ & $\mathbf{p}$ \\
\hline Cured & $16(22.2)$ & $98(37.4)$ & 0.016 \\
Treatment completed & $38(52.8)$ & $136(51.9)$ & 0.896 \\
Defaulted & $10(13.9)$ & $22(8.4)$ & 0.161 \\
Died & $8(11.1)$ & $6(2.3)$ & $0.003 *$ \\
Treatment success & $54(75.0)$ & $234(89.3)$ & 0.002 \\
\hline
\end{tabular}

NB: $*=$ Fishers exact test

\section{Discussion \\ Proportion of TB patients tested for HIV}

This present study showed that all the patients treated for TB had HIV counseling and testing (HCT). This finding is higher than the Lagos state (92.4\%) and national (92\%) figures (NTBLCP, 2014; Daniel et al, 2015). This may be because the study setting was a referral site for TB, HIV and MDR-TB cases in Lagos state and as such it was standard practice at the hospital for all presumptive TB patients to undergo HIV test.

\section{TB/HIV co-infection rate}

In sub-Saharan Africa, the risk of developing TB is high. This is partly due to high HIV prevalence. In 2014, an estimated $41 \%$ of African TB cases were HIV co-infected (WHO, 2014). In this study, 21.6\% had TB/HIV co-infection comparable to Lagos state (23\%) (Daniel et al, 2015), national (19\%) figures (NTBLCP, 2014) and a study from Eastern Nigeria (Njepuome and Odume, 2009) but higher than what was reported in a study from a south-western state in Nigeria (Oladimeji et al, 2013). However southern Africa countries like Malawi and South Africa with high HIV prevalence reported TB/HIV co-infection rate between 56\% - 62\% (WHO, 2014; Tweya, 2013). The prevalence of TB/HIV coinfection was 43\% in Africa (USAID, 2013) and between $50-80 \%$ in parts of sub-Saharan Africa in 2012 (Luetkemeyer and Daley, 2013). Our finding may be a reflection of the decline in the prevalence of HIV prevalence in the country (NACA, 2012) as earlier studies showed that TB/HIV prevalence in Nigeria was between $28 \%$ and $43 \%$ (Daniel and Alausa, 2006; Oshi et al 2014; Njepuome and Odume, 2009; Ifebunandu et al, 2012).

\section{Factors associated with TB/HIV co-infection}

This study showed that TB/HIV co-infection was associated with age group 40 years and above. This is contrary to what was reported in similar studies from Nigeria and Ethiopia, where TB/HIV co- infection was associated with lower age groups (Ofoegbu and Odume 2015; Ige and Oladokun, 2011; Njepuome and Odume 2009; Mekonnen et al, 2015). TB and HIV is known to affect people in the reproductive age groups (WHO, 2014). The reason for the findings in this study is not known, it may be due to sampling variation.

TB/HIV co-infected patients were three times likely to have extra-pulmonary TB (EPTB) than pulmonary TB in this study. Extra-pulmonary TB has been associated with HIV infection (Sterling et al, 2001) because there is increased susceptibility for reactivation and dissemination of TB in these patients (Sterling et al 2001). HIV infection is recognized as the commonest risk factor associated with EPTB and the odds of having EPTB are increased in advanced HIV infection (Jones et al 1993). Our finding differs from what was obtained in a study from Ethiopia which showed that TB/HIV co-infection was associated with pulmonary TB (Mekonnen et al, 2015).

Treatments of recurrent TB are often associated with drug resistance and low cure rates (Unis et al, 2014). TB recurrence depend largely on TB incidence and HIV prevalence (Glynn et al, 2010) and in areas with high TB incidence, 
Adejumo et al., Afr., J. Infect. Dis. (2017) 11 (2): 75-82

https://doi.org/10.21010/ajid.v11i2.10

previously treated TB patients and those with HIV are at higher risk of developing TB from re-infection than the general population and non-HIV people respectively (Millet et al, 2013; Marx et al, 2012). In this study, TB/HIV co-infected patients were 2 times likely to be retreated cases than TB patients similar to what was reported from San Francisco (Payam et al, 2007). A study which used molecular genotyping to distinguish relapse from re-infection showed that HIV patients were five times likely to have TB relapse than non-HIV patients (Nettles et al, 2004).

In this present study, TB /HIV co-infection was significantly associated with poor treatment outcome (AOR: $2.7 ; 95 \%$ CI $1.3-5.41 ; \mathrm{p}=0.006)$. This is incongruent to a study from India that reported comparable treatment outcomes between TB/HIV co-infected patients and TB patients (Suresh et al, 2013). TB/HIV co-infection has been shown to be associated with poorer TB treatment outcomes than TB infection (Daniel and Alausa, 2006; Ofoegbu and Odume, 2015; Tweya et al, 2013; Oshi et al, 2014; Mekonnen et al 2015). Decreased intestinal absorption of antituberculous drugs, TB and HIV drug interaction, pill burden, HIV related stigma, lack of disclosure of HIV status and cost of attending two clinics especially when both clinics are not located within the same hospital have been adduced as possible reasons for poor treatment outcome among TB/HIV co-infected patients (Daniel and Alausa, 2006; Peloquin et al, 1993; Gebremariam et al, 2010; Tadesse et al, 2013; Wares et al, 2003). Severe immune suppression which may increase difficulty of diagnosis and hence delay in treatment initiation may often result in higher mortality among TB/HIV co-infected patients (De Cock et al, 1992).

\section{Limitation}

Some of the records were incomplete and, therefore, were not included for data analyses.

\section{Conclusion}

TB/HIV co-infection rate was high in the study area and it was associated with older age group, retreatment cases, extrapulmonary TB and poor treatment outcomes. The LSTBLCP need to put measures in place that will improve the treatment outcomes of TB/HIV co-infected patients.

\section{References}

1. Daniel, O.J., and Alausa, O.K. (2006). Treatment outcome of TB/HIV positive and TB/HIV negative patients on directly observed treatment, short course (DOTS) in Sagamu, Nigeria. Niger J Med, 15:222-226.

2. Daniel, O.J., Adejumo, O.A., and Abdulrrazzaq, H.A. (2015). Implementation of the Revised Guideline on TB/HIV Collaborative Activities in Lagos, Nigeria. Int J Trop Dis Health, 9: 1-7.

3. De Cock, K.M., Soro, B., Coulibaly, I.M., and Lucas, S.B. (1992). Tuberculosis and HIV infection in sub-Saharan Africa. JAMA, 268:1581-1587.

4. Federal Ministry of Health of Ethiopia. (2009). Tuberculosis prevention and control program, special issue for world TB day. Annual Bulletin, $1: 5-35$.

5. Federal Ministry of Health. Guidelines for the clinical management of TB/HIV related conditions in Nigeria 2nd edition; 2012.

6. Federal ministry of Health. Nigeria STOP TB partnership Strategic plan 2013-2015. 2013 http://www.stoptb.org/assets/documents/countries/partnership/Final\%20. (Accessed December 2016).

7. Federal ministry of Health. National Tuberculosis and Leprosy Control programmes. (2014) Nigeria 2013 NTBLCP Annual report. http://stoptbng.org/wp-content/uploads/2014/08/2013-ANNUAL-REPORT-NATIONALTUBERCULOSIS-LEPROSY-CONTROL-PROGRAMME.pdf (Accessed December 2016).

8. Gebremariam, M.K., Bjune, G.A., and Frich, J.C. (2010). Barriers and facilitators of adherence to TB treatment in patients on concomitant TB and HIV treatment: a qualitative study. BMC Public Health, 10:651. doi: 10.1186/14712458-10-651.

9. Glynn, J.R., Murray, J., Bester, A., Nelson, G., Shearer, S., and Sonnenberg, P. (2010). High rates of recurrence in HIVinfected and HIV-uninfected patients with tuberculosis. J Infect Dis, 201: 704 -711.

10. Ifebunandu, N.A., Ukwaja, K.N., Obi, S.N. (2012). Treatment outcome of HIV-associated tuberculosis in a resourcepoor setting. Trop Doct, 42: 74-76.

11. Ige, O.M., and Oladokun, R.E. (2011). Treatment outcome of newly diagnosed sputum positive adult tuberculosis cases in the context of HIV infection. J Infect Dis Immun, 3:210-217.

12. Jones, B.E., Young, S.M., Antoniskis, D., Davidson, P.T., Kramer, F., and Barnes, P.F. (1993). Relationship of the manifestations of tuberculosis to CD4 cell counts in patients with human immunodeficiency virus infection. Am Rev Respir Dis, 148:1292-1297. 
Adejumo et al., Afr., J. Infect. Dis. (2017) 11 (2): 75-82

https://doi.org/10.21010/ajid.v11i2.10

13. Luetkemeyer, A., and Daley, L. (2013). Tuberculosis and HIV. Comprehensive, upto-date information on HIV/AIDS treatment, prevention, and policy from the University of California San Francisco. HIV in site knowledge base chapter. San Francisco: University of California. http://hivinsite.ucsf. edu/InSite?page=kb-05-01-06 (Accessed November 2016).

14. Marx, F.M., Dunbar, R., Hesseling, A.C., Enarson, D.A., Fielding, K., and Beyers, N. (2012). Increased risk of default among previously treated tuberculosis cases in the Western Cape Province, South Africa. Int J Tuberc Lung Dis, 16: 1059-1065.

15. Mekonnen, D., Derbie, A., and Desalegn, E. (2015). TB/HIV co-infections and associated factors among patients on directly observed treatment short course in Northeastern Ethiopia: a 4-year retrospective study. BMC Res Notes, 8:666 DOI 10.1186/s13104-015-1664-0.

16. Millet, J.P., Shaw, E., Orcau, A., Casals, M., Miró, J.M., and Caylà, J.A. (2013). Tuberculosis recurrence after completion treatment in a European city: reinfection or relapse? PLoS One, 8: e64898-10.1371/journal.pone.0064898.

17. National Agency for the Control of AIDS. HIV prevalence in Nigeria. http://www.naca.gov.ng/nigeria-prevalence-rate (Accessed December 2016)

18. Nettles, R.E., Mazo, D., Alwood, K., Gachuhi, R., Maltas, G., Wendel, K., Cronin, W., Hooper, N., Bishai, W., and Sterling, T.R. (2004). Risk factors for relapse and acquired rifamycin resistance after directly observed tuberculosis treatment: a comparison by HIV serostatus and rifamycin use. Clin Infect Dis, 38:731-736.

19. Njepuome, N., and Odume, B. (2009). The impact of HIV syndromes on the treatment of TB cases in Gombe State, Nigeria. Afr J Respir Med, 5 :17-20.

20. Ofoegbu, O.S., and Odume, B.B. (2015). Treatment outcome of tuberculosis patients at National Hospital Abuja Nigeria: a five year retrospective study. S Afr Fam Pract, 57: 1. DOI: 10.1080/20786190.2014.995913

21. Oladimeji, O., Obasanya, J.O., Daniel, O.J., Gidado, M., Akolo, C., Oladimeji, K., Atilola, O., Ajayi, T., Adeyinka, A., Osman, E., Odusote, T., Awe, A., Lawal, O., Omoniyi, A., Dairo, D., Adedokun, B., Adeoye, I., Igodekwe, F., Hassan, A., and Onoja, M. (2013). Factors Associated with Treatment Success among Pulmonary Tuberculosis and HIV Coinfected Patients in Oyo State, South West-Nigeria. Nig Health J, 13: 75-84

22. Oshi, D.C., Oshi, S.N., Alobu, I., and Ukwaja, K.N. (2014). Profile, Outcomes, and Determinants of Unsuccessful Tuberculosis Treatment Outcomes among HIV-Infected Tuberculosis Patients in a Nigerian State. Tuberc Res Treat, http://dx.doi.org/10.1155/2014/202983.

23. Payam, N., Leah, C.G., Irina, R., Bouke, C., Alon, U.L., Masae, K., Dennis, H.O., Philip, C.H., and Charles, L.D. (2007). Treatment Outcomes of Patients with HIV and Tuberculosis, Am J Respir Crit Care Med, 175: 1199-1206. doi: 10.1164/rccm.200509-1529OC.

24. Payam, T., Ehsan, C., Ahmadreza, M., Parvaneh, B., Majid, M., and Davood, M. (2012). Treatment outcome and mortality: Their predictors among HIV/TB co-infected patients from Iran. Int J Mycobacteriol, 1: $82-86$.

25. Peloquin, C, A., MacPhee, A.A., Berning, S.E. (1993). Malabsorption of antimycobacterial medications. N Engl J Med, 329:1122-1123.

26. Sterling, T.R., Dorman, S.E., Chaisson, R.E., Ding, L., Hackman, J., Moore, K., and Holland, S.M. (2001). Human immunodeficiency virus-seronegative adults with extrapulmonary tuberculosis have abnormal innate immune responses. Clin Infect Dis, 33:976-982.

27. Suresh, S.S., Naik, B., Shet, A., Rewari, B., and De Costa, A. (2013). TB treatment outcomes among TB-HIV coinfections in Karnataka, India: how do these compare with non-HIV tuberculosis outcomes in the province? BMC Public Health, 13:838 http://www.biomedcentral.com/1471-2458/13/838.

28. Tadesse, T., Demissie, M., Berhane, Y., Kebede, Y., and Abebe, M. (2013). Long distance travelling and financial burdens discourage tuberculosis DOTs treatment initiation and compliance in Ethiopia: a qualitative study. BMC Public Health, 13:424. DOI: 10.1186/1471-2458-13-424

29. Tweya, H., Feldacker, C., Phiri, S., Ben-Smith, A., Fenner, L., Jahn, A., Kalulu, M., Weigel, R., Kamba, C., Banda, R., Egger, M., Keiser, O. (2013). Comparison of Treatment Outcomes of New Smear-Positive Pulmonary Tuberculosis Patients by HIV and Antiretroviral Status in a TB/HIV Clinic, Malawi. PLoS One, 8 : e56248. doi:10.1371/journal.pone.0056248

30. Unis, G., Ribeiro, A.W., Esteves, L.S., Spies, F.S., Picon, P.D., Costa, E.R.D., and Rossetti, M.L.R. (2014). Tuberculosis recurrence in a high incidence setting for HIV and tuberculosis in Brazil. BMC Infect Dis, 14:548 DOI: 10.1186/s12879014-0548-6.

31. United States Government agency for international development (USAID). The Twin epidemics: HIV and TB coinfection. http://www.usaid.gov/news-information/fact-sheets/twin-epidemics-hiv-and-tb-co-infection. (Accessed Sep 2016).

32. Wares, D.F., Singh, S., Acharya, A.K., Dangi, R. (2003). Non-adherence to tuberculosis treatment in the eastern Tarai of Nepal. Int J Tuberc Lung Dis, 7:327-335. 
Adejumo et al., Afr., J. Infect. Dis. (2017) 11 (2): 75-82

https://doi.org/10.21010/ajid.v11i2.10

33. WHO. WHO policy on collaborative TB/HIV activities: guidelines for national programmes and other stakeholders. Geneva: WHO; 2012. http:// www.who.int/tb/publications/2012/tb_hiv_policy_9789241503006/en/. (Accessed December 2016.)

34. WHO media center. Tuberculosis fact sheet. Geneva: WHO; 2015. http:// www.who.int/mediacentre/factsheets/fs104/en/. (Accessed November 2016).

35. World Health Organization. Global tuberculosis report 2014. Geneva: WHO. Available from http://apps.who.int/iris/bitstream/10665/137094/1/ 9789241564809_eng.pdf (Accessed December 2016).

36. World Health Organization. (2014) First National TB prevalence survey 2012 Nigeria. http://www.who.int/tb/publications/NigeriaReport WEB NEW.pdf. (Accessed December 2016). 